\title{
3D Printing in Fiber-Device Technology
}

\author{
Louis van der Elst ${ }^{1,2} \cdot$ Camila Faccini de Lima ${ }^{1,2} \cdot$ Meve Gokce Kurtoglu ${ }^{1,2} \cdot$ Veda Narayana Koraganji ${ }^{1,2}$. \\ Mengxin Zheng ${ }^{1,2} \cdot$ Alexander Gumennik ${ }^{1,2}$ (i)
}

Received: 29 September 2020 / Accepted: 2 December 2020

(c) The Author(s) 2021

\begin{abstract}
Recent advances in additive manufacturing enable redesigning material morphology on nano-, micro-, and meso-scale, for achieving an enhanced functionality on the macro-scale. From non-planar and flexible electronic circuits, through biomechanically realistic surgical models, to shoe soles individualized for the user comfort, multiple scientific and technological areas undergo material-property redesign and enhancement enabled by 3D printing. Fiber-device technology is currently entering such a transformation. In this paper, we review the recent advances in adopting 3D printing for direct digital manufacturing of fiber preforms with complex cross-sectional architectures designed for the desired thermally drawn fiber-device functionality. Subsequently, taking a recursive manufacturing approach, such fibers can serve as a raw material for 3D printing, resulting in macroscopic objects with enhanced functionalities, from optoelectronic to bio-functional, imparted by the fiber-devices properties.
\end{abstract}

Keywords Recursive manufacturing $\cdot 3 \mathrm{D}$ printing $\cdot$ Fibers $\cdot$ Optical fibers $\cdot$ Pervasive sensing

\section{Introduction}

Fabrication methods of functional monofilament fibers are numerous, including, but not limited to, extrusion [1], melt spinning [2], and electrospinning [3]. Among the variety of techniques, the thermal draw [4], familiar from the fiber-optics industry, has a promise of delivering highly sophisticated functions within fiber devices due to the freedom in the material-arrangement architecture in the fiber cross-section resulting from this approach. The fabrication of a thermally drawn fiber starts with a preform-a macroscopic object, typically a few centimeters in cross-section

Louis van der Elst, Camila Faccini de Lima, Mengxin Zheng, and Veda Narayana Koraganji equally contributed to the content of this work. Louis van der Elst, Camila Faccini de Lima, and Alexander Gumennik were responsible for editing the manuscript.

Alexander Gumennik

gumennik@iu.edu

1 Department of Intelligent Systems Engineering, Luddy School of Informatics, Computing and Engineering, Indiana University Bloomington, 700 North Woodlawn Avenue, Bloomington, IN 47408, USA

2 Fibers and Additive Manufacturing Enabled Systems Laboratory, 2425 North Milo B Sampson Lane, Bloomington, IN 47408, USA and tens of centimeters to a few meters long. This preform then undergoes a process called a "thermal draw" when it is heated to a state of viscous liquefaction and is spooled into a kilometers-long fiber with cross-sectional features scaled to micrometric or even nanometric regime while preserving the cross-sectional architecture of the initial preform. However complex in its cross-section, the fiber is typically axially uniform and needs to undergo application-specific post-processing if axial patterning is desired [5]. Keeping in mind that conventional preform techniques already result in a variety of non-trivial devices [6-9], and that the functional complexity of the device is directly linked to the fiber's structural complexity, one can imagine what a range of new possibilities a repeatable, digitized, and most importantly, free-form fabrication of preforms by 3D printing will open.

A technique for controlling the 3D architecture of fibers, called VLSI-Fi (or VLSI for Fibers), is described in [5] and combines 3D printing of preforms, which are thermally drawn into fibers, and post-draw assembly of fiber-embedded integrated devices by means of a material-selective spatially coherent capillary breakup of the fiber cores.

Traditionally, the fabrication techniques of multimaterial preforms for monofilament fibers include chemical deposition such as MCVD and PCVD [10, 11], and mechanical stacking [12], with subsequent consolidation 
in both cases. These fabrication methods not only require skilled labor but also limit the geometric complexity of structures that can be realized in fibers. With the advent of additive manufacturing (AM), popularly called 3D Printing (3DP), a layer-by-layer manufacturing process resulting in objects of arbitrary geometric complexity [13], it became an alternative digitized approach to rapid manufacturing of fiber preforms with internal architectures unattainable by the conventional techniques.

AM applications are numerous, spanning but not limited to aerospace, biomedicine, and architecture, owing to cost-effectiveness and the inherent flexibility of the technique $[14,15]$. The growing success of AM also draws the attention of the optical community, and several advanced AM methods have been demonstrated for fabricating both glass and polymeric structures. Here, we review the state of the art in 3D printing, using both polymers and glasses, applied to the fabrication of fiber preforms.

Taking a recursive manufacturing approach, fibers resulting from a thermal draw of 3D printed preforms, optionally embedding functional devices, can be used as a feedstock for 3D printing fiber-based scaffolds, which can manifest active sensing and microfluidic modalities for diverse applications. Some of the latest advancements in this area are around fiber-embedded devices and macrostructures achieved by recursive manufacturing. Worth of highlighting are bioprinting of biomedical scaffolds and tissue engineering, which are important emerging technologies that, we believe, will draw benefit from this approach.

Figure 1 presents a conceptual art exploring the relationships of the fiber-related process we describe in this paper, and how they relate to 3D printing: Through 3D printing, a preform with specific materials and geometry can be designed for the production of fibers via thermal draw (Fig. 1I). In some cases, it might be desirable to post-process the fiber through axial patterning (Fig. 1II) by, for instance, a material selective spatially coherent capillary breakup for the creation of systems of integrated devices of photonic structures in functional fibers, textiles, and wearables - a path currently being explored by several research groups [5, 12, 16-19]. Once the desired functionality has been obtained, the resulting fiber can be used as feedstock for 3D printing functional objects [20] (Fig. 1III), used in bioprinting for the development of biosynthetic interfaces and tissue engineering [5] (Fig. 1IV), in the fabrication of objects with engineered bulk properties [15, 21] (Fig. 1V), or used recursively in the fabrication of a new preform, for example in rescaling bundled fibers as done in [22]. In the figure, the solid lines indicate existing links between the technologies depicted, while the dashed lines suggest some possible hypothetical connections.

\section{D Printed Polymeric Fibers}

In the past six decades, Plastic Optical Fibers (POF's) have seen increased usage in both research and commercial fields owing to their development along with their glass counterparts. Although they suffer from high attenuation, restricting them to short-distance communications, they offer lower costs, easier alignment, and higher flexibility compared to their glass counterparts. Nowadays, POF's are increasingly used in short-distance communication networks like local area networks (LAN's), and due to their higher elastic strain limits, flexibility, sensitivity to strain have opened various sensory applications for these fibers $[28,29]$.

Cook et al. were one of the first to combine 3D printing and fiber drawing in their study. They used FDM (Fused Deposition Modeling) technology to print a cylindrical preform with six holes that are equitangentially spaced at a constant offset from its perimeter using commercially available polystyrene with a transparency $>90 \%$ [25]. This preform was drawn into a fiber, and the attenuation measured in such a suspended-core fiber was comparable to the attenuation in fibers drawn from preforms made using conventional methods, thus demonstrating that $3 \mathrm{D}$ printing can be used for making transmission fibers.

Toal et al. took a step further, printing multimaterial arbitrary cross-section structures to make fiber preforms for the thermal draw [30]. Kaufman et al. made preforms with complex geometry by $3 \mathrm{D}$ printing the fluorescent dye mixed core material (cyclin olefin polymer) and cladding (polystyrene) material and assembling them into preforms [31]. These preforms were thermally drawn into multimaterial fibers, which retained the geometry of the preforms. Then, spherical particles were generated by inducing Plateau-Rayleigh instabilities in the core material. The resultant particles were still able to retain, although with some deformation, the geometry of the preform. Fabrication of complex-geometry multimaterial structures by conventional methods is timeconsuming and, in some cases, is hardly accomplishable, making the AM an irreplaceable tool for the creation of complex geometries in fibers. Some examples of cross-sections of 3D printed polymeric preforms and resulting fibers are shown in Fig. 2I, III, IV. Luo et al. offer a comprehensive and exhaustive study on 3D printed polymers [32].

Multimaterial fiber draw is a complex fluid dynamics phenomenon. Materials with dissimilar viscosities, interfacial energies, and cross-sectional feature dimensions, arranged in a complex geometry are expected to flow in an orderly fashion, such that the fiber cross-section geometry, as it is descending from the preform, is preserved. In reality, there is a number of physical mechanisms, from capillary instabilities $[33,34]$ to radially non-uniform material 


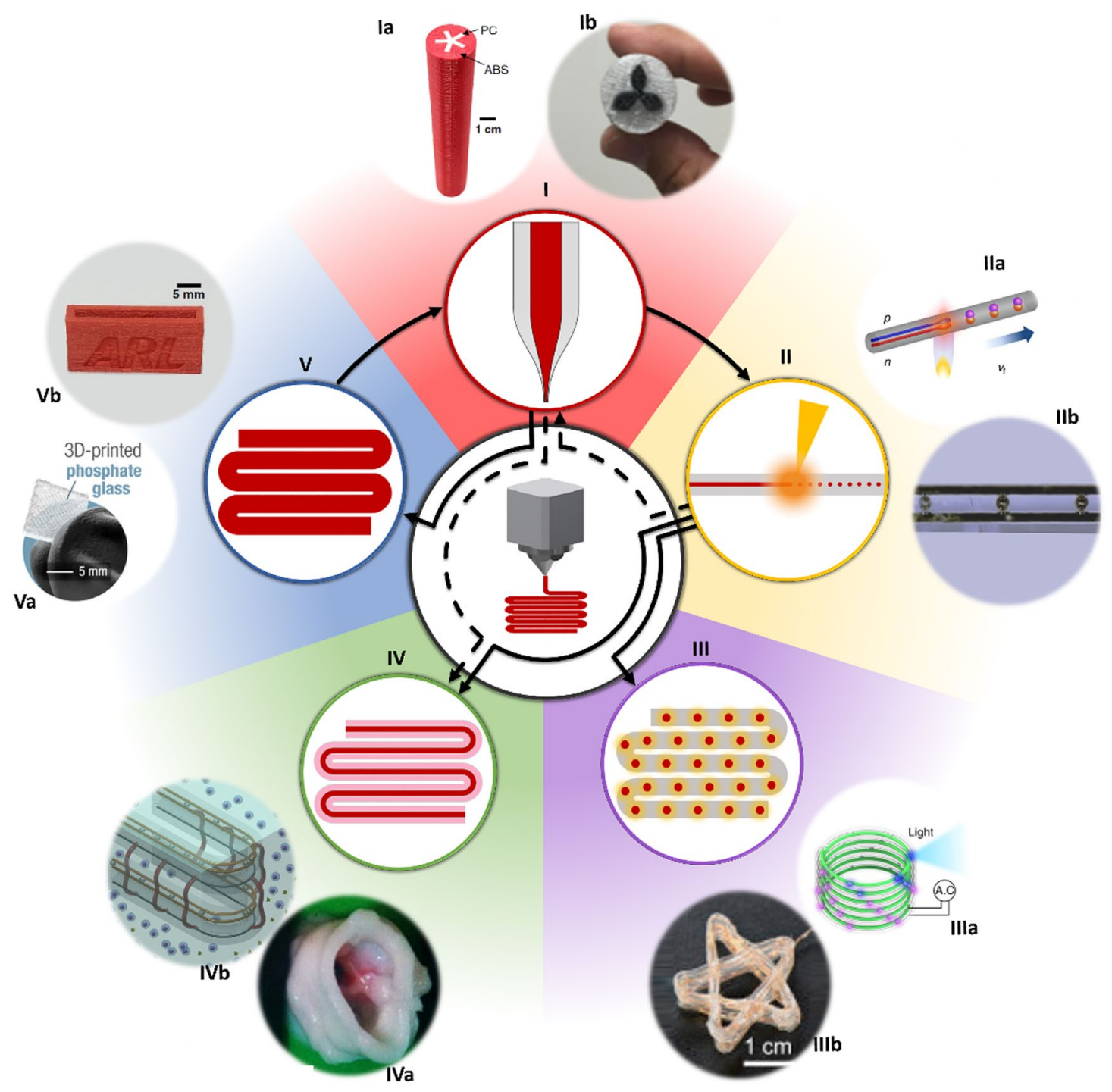

Fig. 1 Conceptual art exploring the connections (solid arrows), as well as possible ones (dashed arrows), between different applications of 3D printing (center) in fiber device technologies, and examples from the literature (outer layer). I Fiber draw from a preform prepared by $3 \mathrm{D}$ printing and/or stack-and-draw, leading to unconventional fiber cross-sectional geometries and materials [20, 23, 24]. Ia and Ib Examples of 3D printed preforms, from [21] and [25], respectively. II Axial patterning of multimaterial fibers via the material-selective capillary breakup, described in [5], enabling functional fibers, textiles, and wearables [5, 16-19]. IIa Illustration of pn junction fab-

flow [35] that challenge this expectation. Though complex geometries are achieved by 3D printing, the anisotropic porosity inherent to the $3 \mathrm{D}$ printing process and the resulting anisotropic thermodynamic and mechanical behavior of the preforms during the thermal draw is not considered. Yet, porosity is a specific instance of multimaterial arrangement, thus needs to be considered, in an isolated fashion, for structural deformation effects on the fiber draw process. Indeed, it is apparent that the draw of as-printed rication through capillary breakup, from [19]. IIb In-fiber array of spheres contacted in parallel [18]. III Functional 3D objects from structured fibers. IIIa Light emitting system [20]. IIIb 3d structured printed with elastic triboelectric fiber [26]. IV Biosynthetic interfaces, bioprinting, and tissue engineering [5]. Iva Conceptual drawing of smart fibers integrated to living tissue [5]. IVb $3 \mathrm{~d}$ printed aortic valve [27]. V Objects with engineered bulk properties. Va 3d printed phosphate glass piece [15]. Vb $3 \mathrm{~d}$ printed part with multimaterial filament [21]

preforms is prone to significant structural deformation to the fiber cross-section, as stems from the comparison of preforms to the fibers in Fig. 2I, III, IV. Deformation, inturn, can adversely affect the fiber-device performance in cases where the geometry defines the function. To eliminate the influence of porosity on the drawing process, we have introduced an annealing step to the 3D printed preform prior to the draw, which improved the structural and did not diminish the optical properties of the fibers [23]. 

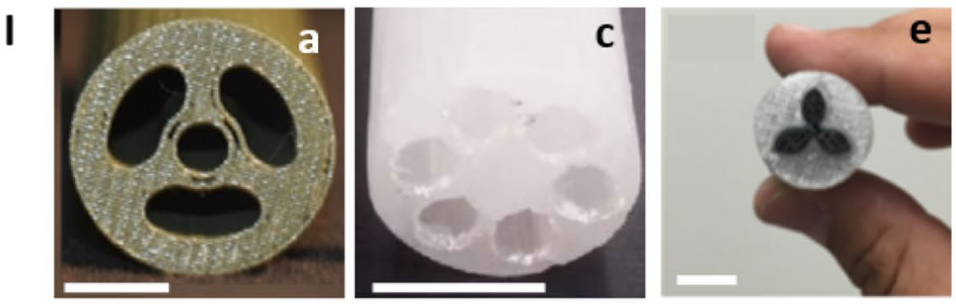

II
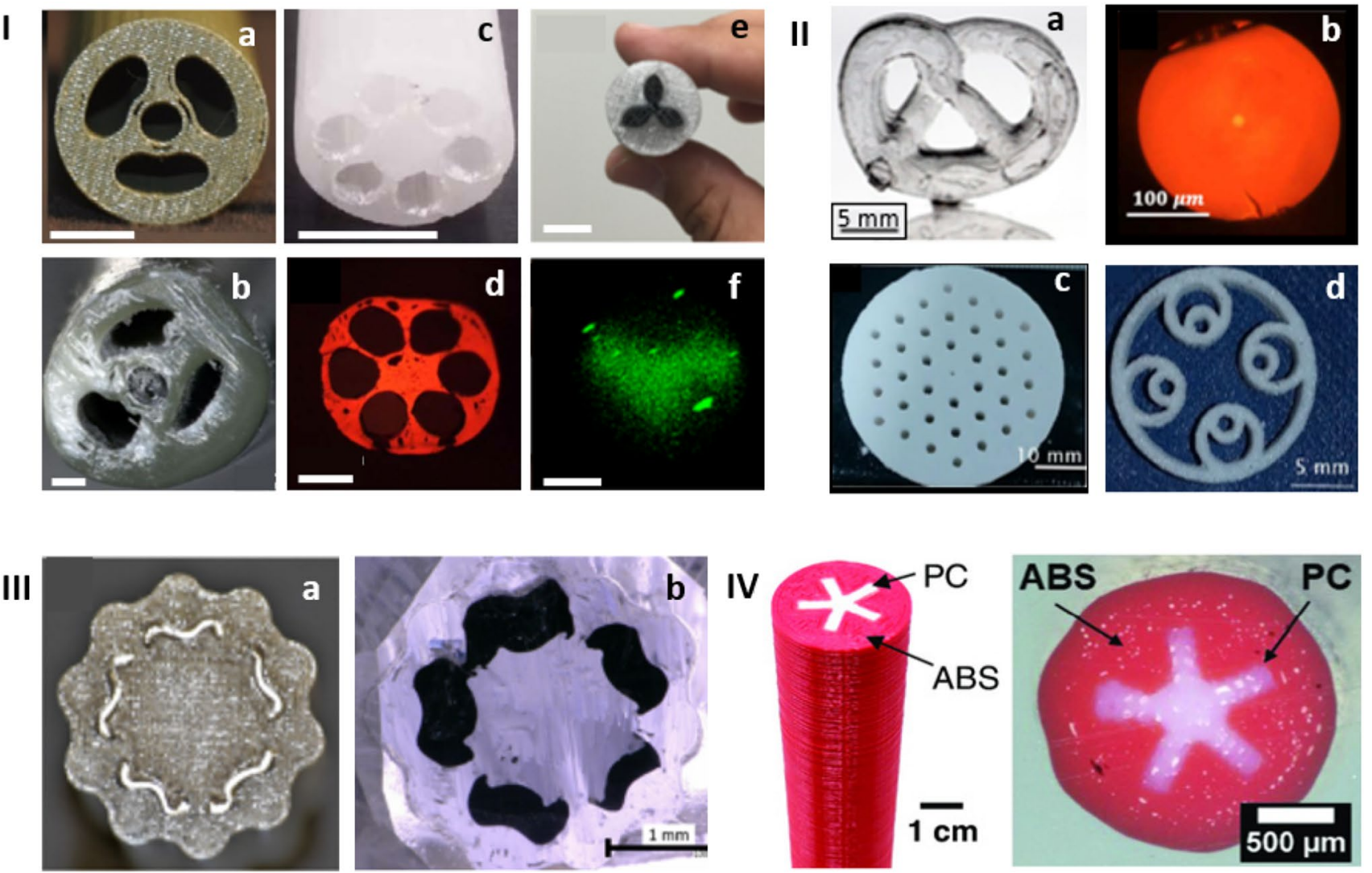

Fig. 2 Fibers from 3D printed preforms: I Polymeric fibers from 3D printed preforms: Ia ABS preform with multiple channels (scale bar $=1 \mathrm{~cm}$ ) and $\mathbf{I b}$ cross-section image of the fiber with a glass optical fiber in the central channel (scale bar $=200 \mu \mathrm{m}$ ), adapted from [30]). Ic Air structured, solid core preform with six equitangetially spaced holes, made of styrene butadiene copolymer (scale bar $=1 \mathrm{~cm}$ ) and Id optical fiber cross-section resulting from preform shown in Ic), with $630 \mathrm{~nm}$ laser coupled at other end of the fiber (scale bar $=200 \mu \mathrm{m}$ ) adapted from [25]). Ie Propeller core-shell preform made of polystyrene cladding and fluorescent dye-doped cyclic olefin polymer ( scale bar $=1 \mathrm{~cm}$ ) and If confocal fluorescence microscopy image of the particles produced from the drawn fiber resulting from the preform shown in Ie) (scale bar $=10 \mu \mathrm{m})$, adapted from [31]. II
3D printed glass objects preforms, and fibers from 3D printed glass preforms: IIa Example of printed and sintered glass pretzel structure with SLA technology, adapted from [41]. IIb Fiber cross-section image of 3D printed multi-mode fiber with DLP technology, from [49]. IIc and d Preforms for Photonic Crystal Fiber and Antiresonant Fiber produced by SLS technology, adapted from [50]. III Retrorefelctive fiber from 3D printed preforms: IIIa Preforms printed with PC and 5 channels filled with Indium and IIIb microscopic image of the drawn fiber in transmission mode, adapted from [36]. IV Dual material fiber: IVa Dual Material preform with ABS cladding and PC core in asterisk pattern and $\mathbf{I V b}$ dual material fiber drawn from the preform shown in IVa), from [21]
We first start with 3D printing pairs of identical preforms with square cross-sections $1 \mathrm{~cm} \times 1 \mathrm{~cm} \times 25 \mathrm{~cm}$ using polycarbonate (Stratasys PC-10) in an FDM printer (Stratasys Fortus $450 \mathrm{mc})$ at different print orientations. Two types of preforms were investigated for the draw-related deformation effect: those in which the $1 \mathrm{~cm} \times 1 \mathrm{~cm}$ facet is printed in parallel to the print bed (Orientation A), and those in which $1 \mathrm{~cm} \times 25 \mathrm{~cm}$ is printed in parallel to the print bed (Orientation B). The construct layer thickness was $177 \mu \mathrm{m}$. One of the resulting preforms in each pair is then annealed at $165{ }^{\circ} \mathrm{C}$ in a vacuum furnace for $32 \mathrm{~h}$, and the other one is kept non-annealed for reference. In the course of the annealing process, the preforms were manually rotated by $180^{\circ}$ around the preform's longest axis at 8-h intervals to minimize the sag caused by the gravity-induced flow, which becomes non-negligible at such proximity to the glass transition temperature.

The preforms are then thermally drawn into fibers, as is demonstrated in Fig. 3I, II, while the $1 \mathrm{~cm} \times 1 \mathrm{~cm}$ facet of the preform is perpendicular to the draw direction. The fibers resulting from annealed preforms are compared to those resulting from non-annealed preforms, as is demonstrated in Fig. 3III, for investigation of structural effects of annealing on the fiber cross-sectional geometry.

The draw of non-annealed preforms printed in Orientation A consistently fails due to layer delamination. Fiber rupture due to layer delamination has been discussed in detail in our previous work [5] and has been verified here. 
More importantly, annealing is found to eliminate this effect completely. The annealed preforms printed in Orientation A result is successful large-scale draws, in which the square geometry of the cross-section is preserved by the draw: square preform cross-section yields a square cross-section of a fiber.

A qualitatively different effect takes place in the draw of the preforms printed in Orientation B. Fibers from such non-annealed preforms suffer structural deformation of the cross-section: a square preform cross-section yields a fiber with a rectangular cross-section (Fig. 3IIIa). In the drawing process, the cone section, in which the fiber scales down from the preform, the necking is uneven: the $1 \mathrm{~cm}$ wide facet that was printed in perpendicular to the print bed scales down faster than the $1 \mathrm{~cm}$ facet printed in parallel to the print bed. We argue that this effect takes place due to the anisotropic porosity inherent to the $3 \mathrm{D}$ printing process. The infill is denser in-plane with the print bed, corresponding to the cross-section facet designated as Y in Fig. 3, than along the direction perpendicular to the print bed, designated as $\mathrm{X}$. When heated to become a viscose liquid, the viscosity of the draw cone is non-isotropic. It is denser, and thus more viscous along the cross-sectional direction that was printed in-plane with the print bed, i.e. along Y.

In order to study the effect of annealing on the structural deformation of the fiber cross-section, the cross-section scaling along the draw cones of non-annealed and annealed preforms was analyzed in MATLAB by mapping each crosssectional facet boundaries alone the draw-cone and calculating the evolution of width ratio of orthogonal cross-sectional facets, i.e. Y/X, alone the draw cone, as shown in Fig. 3III. The facet width ratio in the non-annealed preform draw-cone increasingly deviates from unity, as descending from the preform into the fiber. This deviation indicates a reshaping of an initially square preform into a rectangular fiber. Conversely, in an annealed preform draw-cone, this deformation effect is within the error range.

In terms of optical transmission loss, there is not a significant difference between fibers resulting from non-annealed vs. annealed preforms, as is evident from Fig. 3IV. Both dissipate the light through the circumference, thus can potentially be utilized as side-illumination fibers [23].

Apart from direct annealing of 3D printed preforms, few other methods have been developed in recent years that minimize the structural deformation of the cross-section of fibers from 3D printed preforms. Ghebrebrhan et al. have been successful in making retroreflective fibers from 3D printed preforms with low structural deformation [36] (Fig. 2III). Their preform consists of 3D printed core and cladding in polycarbonate (PC), with channels in-between that are filled with Indium. These materials were chosen such that the melting point of the metal and the glass transition temperature of the polymer cladding are comparable. The printing parameters have been adapted to allow for concentric circular paths with respect to the core of the preform, to decrease the deformation caused by outward hydrostatic pressure from molten Indium on the cladding during thermal draw. Furthermore, the temperature of the furnace during the draw was selected to balance the viscous flows of the preform materials, ensuring cross-sectional shape retention.

As mentioned previously, another area that can greatly benefit from structured fibers from 3D printed preforms is the engineering of bulk properties in macroscopic objects. Such an approach is exemplified by the work of Hart et al. [21], where a dual material fiber with structured cross-sectional geometry was prepared via preform $3 \mathrm{D}$ printing, and subsequently used for the manufacturing of objects traditionally made with injection molding, achieving enhanced mechanical properties. The preform, shown in Fig. 2III, was monolithically printed, using a 3D printer capable of extruding the two materials at once. The outer cladding is printed in acrylonitrile butadiene styrene (ABS) while the core is printed in PC. The fiber drawn from this preform was able to maintain the cross-sectional features of the preform with very low deformation, which was achieved by low draw temperatures. The impact of draw temperature and the playoff between the viscous forces and surface tension forces in the shape retention of the fiber is explored in more detail in the following section.

\section{D Printed Glass Fibers}

Glasses have many appealing properties, such as outstanding optical transparency, superior mechanical and chemical properties, and extremely low thermal expansion [37]. These attributes make the glass applicable to a range of areas in scientific research, industry, and societally marked fields, including optics, electronics, and communication [38-40]. Structured silica fibers dominate many applications, such as optical fiber communication, phytochemical detection, and tight focusing of light [5]. As such, there is a drive to manufacture silica fibers with complex cross-sectional geometries. However, this is hard to achieve by conventional methods, for example, high-temperature melting, chemical vapor deposition, and etching [14, 41, 42]. Also, as many post-processing steps are often needed, such as careful consolidation of a bare preform, the process is time and labor-intensive.

One of the earliest reports on 3D printing transparent glass is through selective laser sintering (SLS) technology by Luo et al. with soda-lime glass on depositing layered singletrack wide walls, while only a coarse structure with $\sim 1 \mathrm{~mm}$ resolution was obtained [43]. Klein et al. firstly developed a molten glass material 3D extrusion system inspired by fused deposition modeling (FDM) technology [44]. They succeed in printing complex-structure glass with varying color, while the layer thickness is $4.5 \mathrm{~mm}$, which rules out its application 

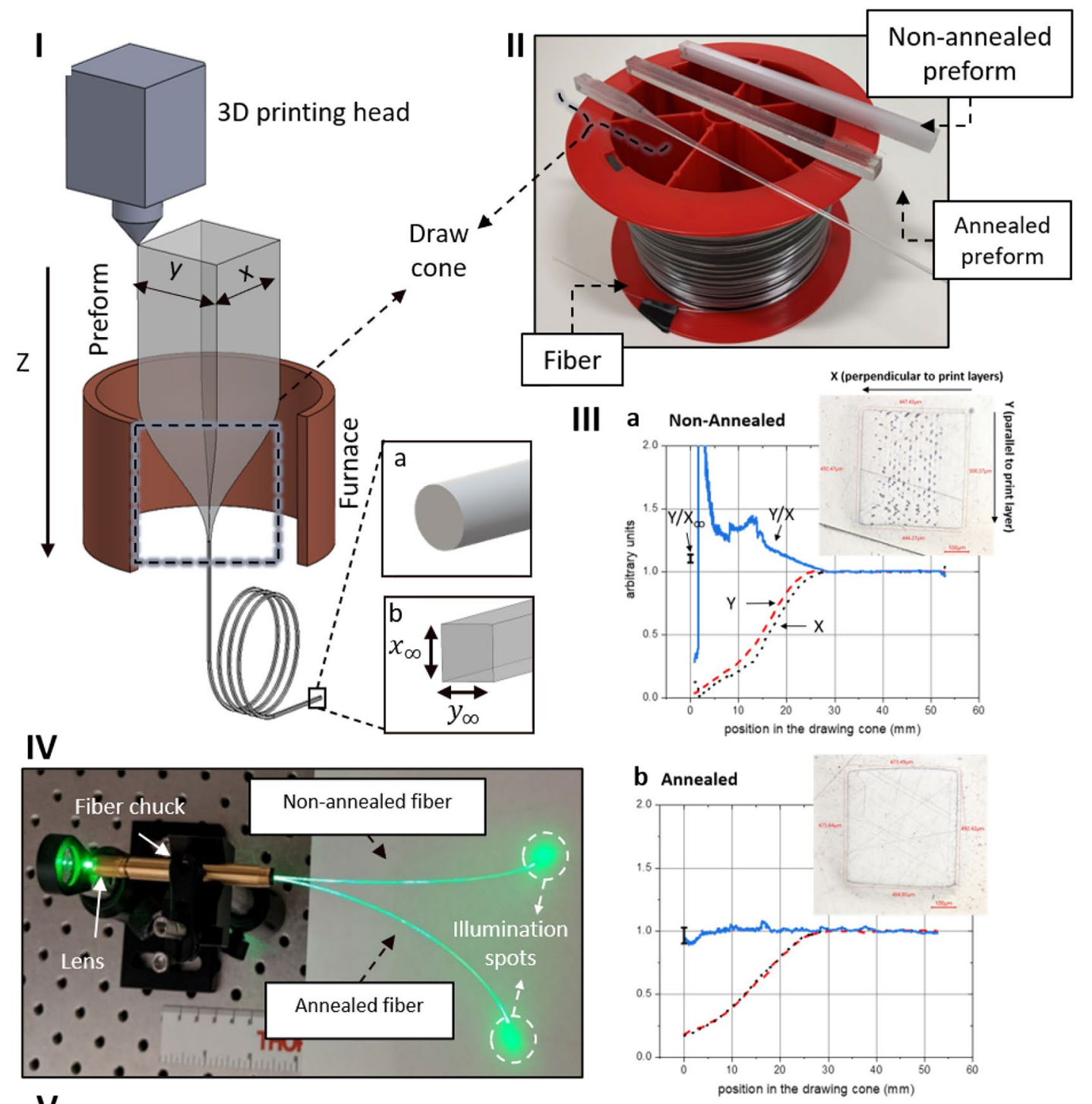

V
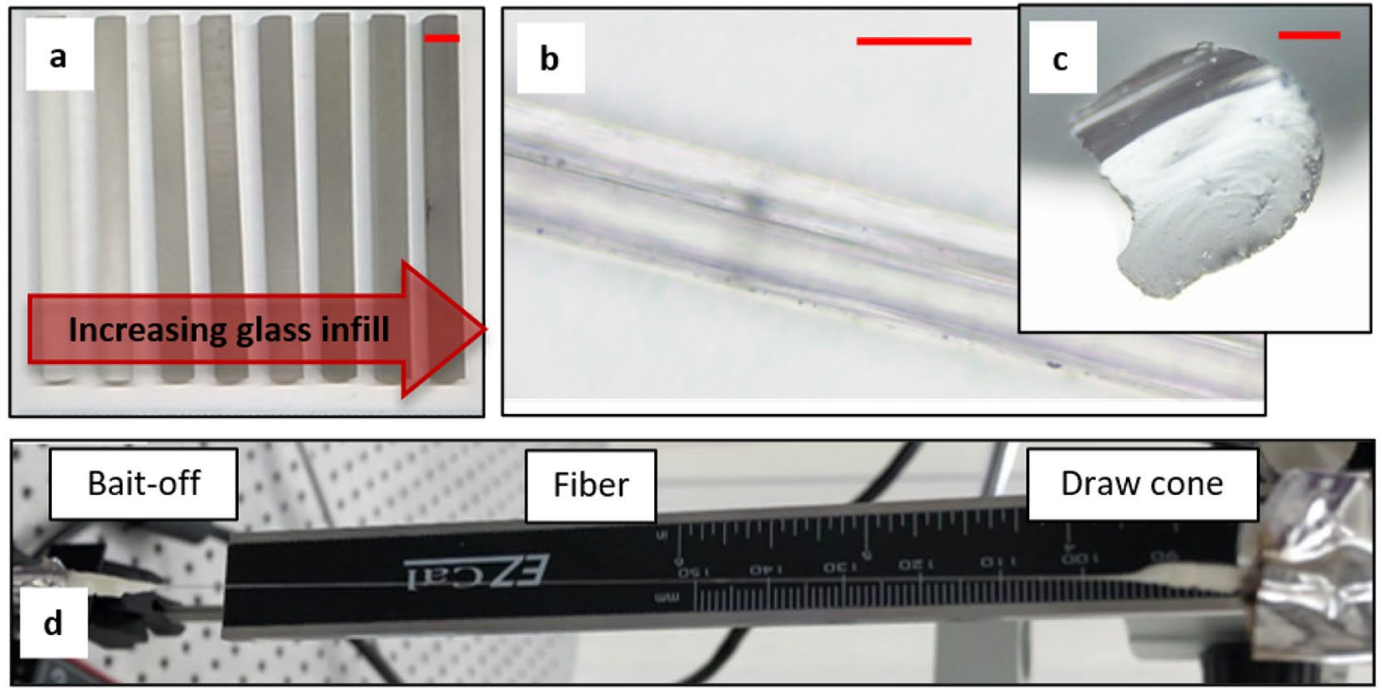
4Fig. 3 I Illustration of 3D printed preform with non-equilibrium cross-section and thermal draw process, resulting in a fiber that Ia deforms into cylindrical shape when surface tension overcomes the viscous forces during thermal draw of the preform or Ib preserves the cross-sectional geometry of the preform when viscous forces dominate surface tension during thermal draw. II Illustration of optically transparent annealed and opaque non-annealed 3D printed PC preforms with square cross-section, draw cone after fiber draw and resulting fiber. IIIa Non-annealed and IIIb annealed 3D printed square preform draw analysis: Progression of thicknesses as a function of position along the draw cone in two cross sectional orientations is labelled as $\mathrm{X}$ and $\mathrm{Y}$ for both non-annealed and annealed draw cones. The ratio of cross-sectional thicknesses is demonstrated for both cases as function of the position along the drawing cone (Y/X). The error bar $\left(\boldsymbol{Y}_{\infty} / \boldsymbol{X}_{\infty}\right)$ shows the asymptotic ratio derived from the resulting fibers' cross-sections analysis. The insets show optical micrographs of fiber cross sections for the non-annealed and annealed $0^{\circ}$ preforms, respectively. The residue of $3 \mathrm{D}$ printed structure is evident in the cross section of the fiber drawn from non-annealed preform, adapted from [23]. IV Optical loss comparison: A collimated laser beam coming from the left is focused on to fibers drawn from $0^{\circ}$ annealed and non-annealed PC preforms, where it can be seen that light is emitted by the fiber sides on both cases. Illuminating spots on a white paper, highlighted with dotted circles, indicate that these fibers transmit light, adapted from [23]. V Fiber from 3D printed soda-lime glass preform: Va 3D printed soda lime glass preforms with increasing glass infill (from left to right), from 0 to $35 \% \mathrm{vol}$ (scale bar $=4 \mathrm{~mm}$ ), adapted from [5]. Vb Microscope image in transmission mode of the drawn fiber (scale bar $=100 \mu \mathrm{m}$ ), adapted from [24]. Vc Fiber cross-section from region close to the draw cone (scale bars $=100 \mu \mathrm{m}$ ), adapted from [24]. Vd Drawn fiber (image rotated $90^{\circ}$ clockwise), adapted from [24]

in optics and photonics where a micrometric resolution to the very least is required. Researchers around the globe are persistent in their efforts to develop original, increasingly non-conventional approaches to 3D printing of glass. Kotz et al. have developed a customized composite resin for printing via stereolithography (SLA), mixing a nanoscale silica powder into a liquid photocurable monomer. Post-printing treatment involves baking-off the polymer and sintering the silica particles to densify the residual glass [45] (Fig. 2IIa). Nguyen et al. used a direct ink writing process to 3D print silica glass structures [46]. Aligned with this idea, Moore et al. have recently reported a 3D printing of silica-based glasses with controlled chemical compositions relying on the sol-gel-like process of phase separation in hybrid resins via digital light processing [47].

Furthermore, beyond preform fabrication, drawing fiber directly from a 3D printed preform has been proposed and demonstrated by Canning et al. [48], where they first used acrylonitrile butadiene styrene (ABS) to get coreless optical fibers with standard losses. Later, the same research group applied direct light processing (DLP) to obtain a glass perform [49]. After the debinding process, the preform was inserted into a quartz tube to provide structural support and drawn into a fiber. The optical loss in the resulting fibers (Fig. 2IIb) is $\sim 24 \mathrm{~dB} / \mathrm{m}$ at $532 \mathrm{~nm}$, which is quite high owing to the non-optimized fabrication processes. Sintering of the preform to transparency prior to drawing would arguably reduce the propagation losses in such a fiber. Sahu et al. have recently reported the fabrication of complex glass preform structures for a photonic crystal fiber (Fig. 2IIc), an antiresonant fiber (Fig. 2IId), a multicore fiber, and a multi-material fiber in a custom-developed SLS 3D printer [50], awaiting a demonstration of a successful draw.

It is important to highlight, however, that the aforementioned 3D printed objects and resulting fibers, shown in Fig. 2IIb-d consist primarily of a combination of equilibrium, i.e. cylindrical, cross-sectional features. Since the fiber draw is a liquid phase process, there are two forces that compete in this process: viscosity and surface tension. The surface tension will drive the reshaping of any nonequilibrium cross-sectional shape to a geometry that minimizes the surface energy. In the case of axially uniform fiber, quasi-equilibrium geometry is a cylinder (Fig. 3Ia). On the other hand, the viscosity force will drive the preservation of the original cross-section geometry (Fig. 3Ib). The interplay between these two forces is dictated by the material characteristics and draw conditions, so being able to manipulate these parameters is key to controlling the fiber cross-sectional geometry. In work presented by Zheng et al. [24], a square preform is used as a study system for controlling the fiber cross-section in the thermal draw. Soda-lime glass fiber preforms were printed using SLA process utilizing commercial printing resins. To obtain the soda-lime glass prints, a mixture of clear resin (Formlabs FLGPCL04 Clear) with milled soda-lime glass fibers (\#38 Fiber Glast) was used for the printing process with the volumetric glass infill of up to $35 \%$ in the liquid resin (Fig. 3 Va), resulting in an infill of up to $38 \%$ in the printed preform [5]. After printing, to remove excess resin, the parts were immersed in isopropanol (IPA) for $10 \mathrm{~min}$, and post-cured with UV light for $30 \mathrm{~min}$ at $60{ }^{\circ} \mathrm{C}$. The printed part is thermally treated to burn out the polymer at $600{ }^{\circ} \mathrm{C}$ and to sinter the remaining glass to be densified part at $950{ }^{\circ} \mathrm{C}$ holding $3 \mathrm{~h}$. Each end of the sintered preform welds to borosilicate rods at mounted pillar posts for consistent alignment. Then, we use a custommade setup equipped with a hydrogen-oxygen torch to draw preforms into fibers (Fig. 3Vd). The ensemble was vertically suspended, and the preform was heated with the torch, resulting into its draw into a thin fiber. Figure $3 \mathrm{Vb}$ and $\mathrm{c}$ show an optical microscope image of the drawn fiber and its cross-section, respectively. We can see that one side of the fiber (which was facing the torch) has a more rounded shape, while the other has a more irregular shape that reflects that of the preform pre-draw. We believe that minor improvements of draw setup will meliorate the cross-section deformation and retain the pre-draw shape. The results presented by Zheng et al. [24], however, demonstrate the viability of the approach for 3D printing glass preforms. Although the study here was focused on the soda-lime glass, the method 
is flexible in the material of choice and is easily translatable to other silica-based glasses.

\section{Recursive Manufacturing}

Recursive manufacturing in the context of the current review refers to the use of the fibers obtained from a thermal draw in either the fabrication of new fiber preforms or as a step in the production of objects through AM. These can be as simple (yet effective) as bundling fibers in a new preform for an additional draw, scaling down the original fiber crosssection-a technique used by Yaman et al. [22] to produce long and uniform nanowires and nanotubes (Fig. 4I).

Furthermore, in the past couple of decades, increasing attention has been given to the fabrication of nanodevices, with notable developments in micro-electro-mechanical systems (MEMS) [51], and devices assembled from core-shell particles and nanowires [52], fueled by advancements in nanomaterial technologies [53]. However, nanotechnology, while tremendously developed on the level of individual devices, many times lacks in strategies for integration of those into macroscale systems, which would open the way for many useful products.

Multimaterial fiber devices manifest nanometric and macroscopic characteristics simultaneously-while being many kilometers long, they possess nanometric cross-sectional feature dimensions. This makes fibers natural candidates for nano-to-macro integration, where electronic and optoelectronic capabilities can be achieved through careful preform design and processing as explored by Abouraddy et al. [12], as well as by applying post-processing methods to as-drawn fiber, such as pressure-assisted melt filling and high-pressure chemical vapor deposition (HPCVD) [54]. Integrated arrays of fiber-embedded devices can also be selfassembled through an axial patterning of initially continuous cores by a material selective capillary breakup [18, 19, 55], and manipulation of said devices through thermocapillary convection [56]. These approaches allow for the creation of arrays of complex-architecture devices contacted in parallel
I
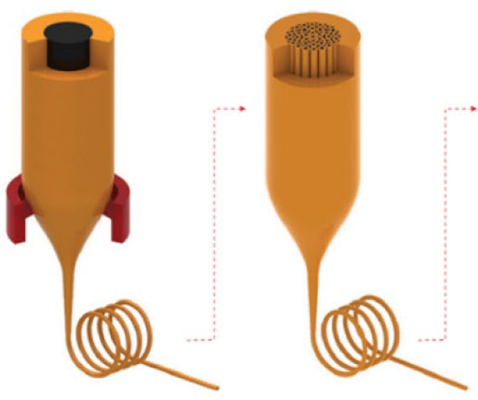

- semiconductor

- dielectric

\section{III}

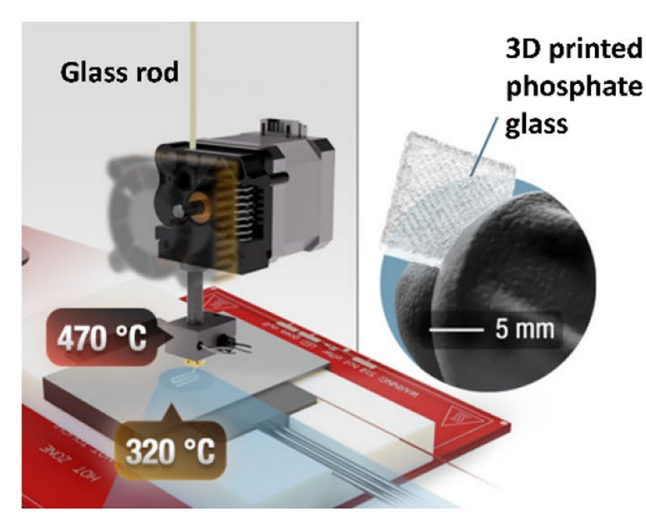

Fig. 4 Recursive Manufacturing: I Nanowire fabrication schematic illustration, via scaling-down of fibers-in-a-bundle, adapted from [22]. II Schematic illustration of the fabrication process of soft transmission lines and the weaving of the resulting fiber into the fabric, demonstrating flexibility and stretchability, adapted from [59]. III
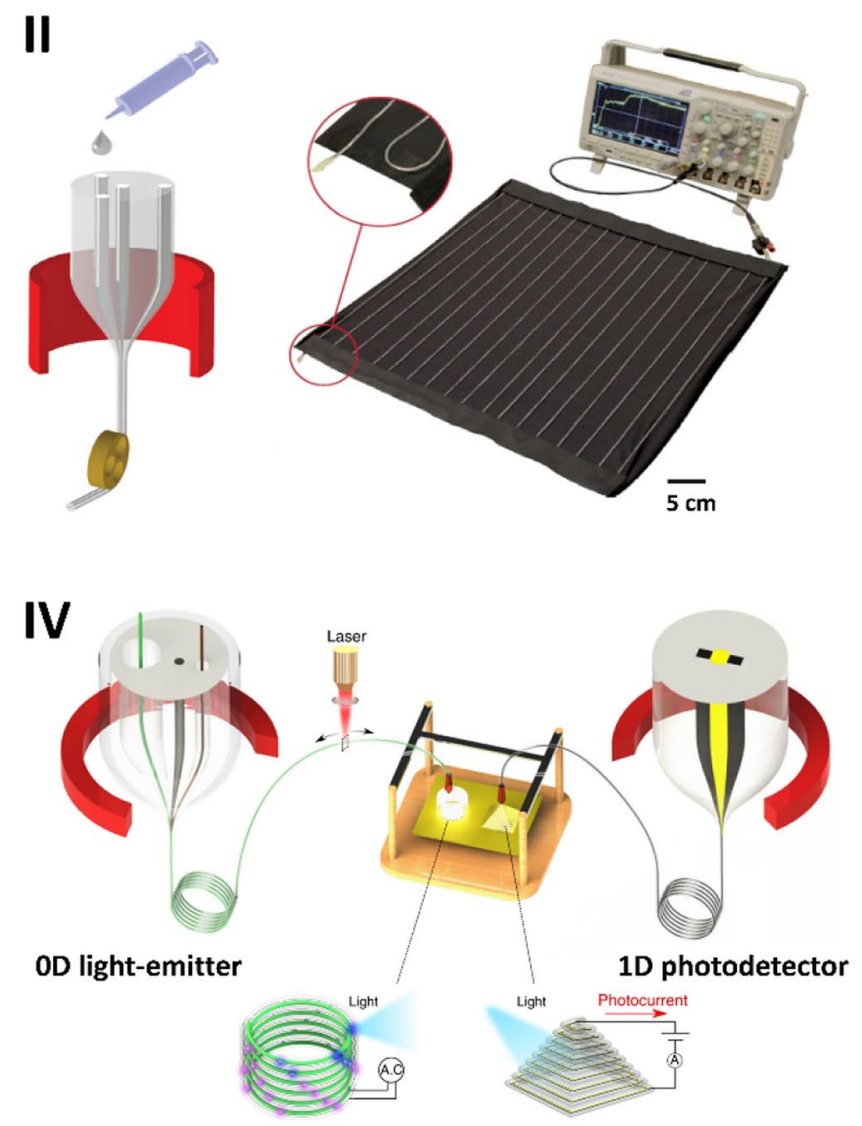

Phosphate glass fiber fabrication via a thermal draw, and its subsequent use in FDM 3D printing for the fabrication of designed glass parts, adapted from [15]. IV Structured fiber fabrication and subsequent use as multimaterial structured filament in 3D printing of objects with embedded electronic functionalities, adapted from [20] 
spanning the entire fiber length. Another great example of integration of in-fiber nanomaterials is shown in Yan et al. [57], where the authors demonstrate a fiber with novel optoelectronic capabilities, achieved through self-assembly of semiconducting nanowires with built-in fiber electrodes.

Furthermore, nanodevices might be integrated into the fiber during the drawing process, as done by Rein et al. [58], where semiconductor diodes are incorporated into flexible fibers by embedding the devices in the preform before the thermal draw. In addition, several examples of integration of functional fibers in the area of flexible electronics are explored in detail by Yan et al. [4], emphasizing the readily available technologies that make such integration to everyday objects not only a possibility but a reality. Leber et al. provide an excellent demonstration of this concept in [59], where stretchable transmission fibers are fabricated and then woven into fabrics for the creation of a flexible electronic textile able to detect deformations and pressure points (Fig. 4II).

AM of fiber preforms allows for complex geometries and material compositions unattainable with conventional methods. As the functional complexity of the fiber device largely correlates with the architectural flexibility of the fiber preform, monolithic and precise Direct Digital Manufacturing of fiber preforms is a key factor for enabling Moor's law dynamics in the realm of functional fibers and fabrics, further expanding the possibilities of in-fiber device designs as discussed in [5].

Due to their unique form factor, fibers can be readily integrated into everyday objects to enhance their functionality [60, 62, 62]. Furthermore, multimaterial and structured fibers can be used as feedstock for 3D printers, enabling the construction of various macroscale objects with active embedded devices while retaining the nanoscale crosssectional features and functionalities of the fiber, including fiber-based scaffolds with active sensing and microfluidic modalities for biomedical and tissue engineering applications. 3D printing also offers the advantage of allowing the spatial arrangement of the desired features in the printed objects: for example, one could take the nanowires produced by the stack-and-redraw method [22] and arrange them in an arbitrary predesigned fashion to obtain specific geometries and orientations, eliminating the constraint of having the nanowires in a parallel. Moreover, as observed in [23], the inherent characteristics of 3D printing, especially the infill factor, can define periodic structures that might be used in photonic applications in the future.

This recursive manufacturing approach can also enable the use of non-conventional materials in 3D printing, such as glasses, as explored by Zaki et al. [15], where thermally drawn phosphate glass fibers were used in the 3D printing of optically transparent structures (Fig. 4III). Another interesting example is provided by Hart et al. [21], where a dual material (DM) fiber was used as feedstock for 3D printing objects traditionally manufactured using injection molding. The thermal properties of the materials used, as well as the designed cross-sectional geometry, allowed for a finished part with significantly improved mechanical properties when compared to a traditionally prepared part.

Notably, in [20], Loke et al. describe an approach for 3D printing of designed hierarchical functional systems using multimaterial fibers as structured filaments, coated by an adhesion layer. This approach allows not only the co-printing of disparate materials but also the seamless integration of discrete electric activated light-emitters, achieved by the infiber capillary breakup, into macroscopic objects (Fig. 4IV). Moreover, the authors also demonstrate 3D printed light sensors, using a photodetecting fiber as filament.

A similar approach is taken by Tong et al. [26], where flexible silicone fibers with a copper core were produced directly by micro-extrusion during the $3 \mathrm{D}$ printing process of various 3-dimensional objects. These triboelectric nanogenerator (TENG) fibers were successfully applied in realtime mechanosensing of organ edema, as well as in speech recognition in the absence of sound.

These studies exemplify the tremendous potential of recursive manufacturing in the creation of novel sensing mechanisms, energy harvesting and other functional modalities in fibers and fiber-based wearables and devices.

\section{Emerging Technologies}

\section{Review of Bioprinting}

The more intricate and novel type of additive manufacturing is the printing of $3 \mathrm{D}$ constructs of biological and living materials. The first inkjet 3D printing technique came to light with Gottwald's liquid metal recorder in 1971 [62], and bioprinting was first demonstrated using the same fabrication technology in 1988 by Klebe's cytoscribing printer [63]. Bioprinting has since progressed to be performed with other types of automated technologies with a general vision of applications in transplantation and regenerative medicine. We provide here a quick overview of key interdisciplinary considerations in bioprinting. Successful bioprinting depends on a good understanding of its printing automation, cells and living organisms involved, and the desired end tissue result. Cells must be assessed in terms of their biological behavior, rate of proliferation, density, types and ratios, and supplied biomolecules such as growth factors and nutrients. The tissue scaffold and extracellular matrix must be planned according to its potential bioactivity, biomimicry, mechanical and structural properties, and self-assembly. The chosen solution depends on a variety of engineering factors and faces many challenges such as the biomaterial 
printability, biocompatibility and interaction, scaffold degradation and dissolvability rates, and potentially hazardous and infectious byproducts. Furthermore, the process faces challenges regarding the control of scale, time, precision, reproducibility, and human errors. Unlike inert materials, living organisms cannot be synthetically created to this day and are perpetually active, similar to the extracellular matrix of a tissue that constantly remodels itself to preserve homeostasis. Hence, the bioprinting process requires equally important pre- and post-processing stages. In the pre-bioprinting process, the desired cell types have to be cultivated and incubated into the desired density within a biological ink or into spheroids, for example. During the bioprinting process, a variety of computer-aided fabrication techniques are used to place the cells into a specific three-dimensional arrangement. Alternative methods involve seeding the cells in a bioreactor after printing a biocompatible material. In the post-bioprinting process, the tissue construct has to mature to become the desired tissue. Most of the printed structures have proven their use in simple bioactive implants or in-vitro studies. A plethora of strategies for bioprinting has already been evaluated in previous reviews [64-67].

The biomaterial used for printing is typically a compound material made of constituent elements holding significantly different physical and chemical properties that mimics the extracellular matrix. The extracellular matrix is a large network of proteins facilitating cellular adhesion, communication, and differentiation. These proteins are, in general, structural proteins such as collagen or elastin, specialized proteins such as fibrillin or fibronectin, proteoglycans such as heparin sulfate or chondroitin sulfate, and cytokines such as growth factors [68-71]. Due to the independent evolution of various multicellular lineages, the morphology and composition of an extracellular matrix from one organ to another is very different. And thus, the biomimicry of such material also radically changes based on the targeted tissue and cells to print. A large library of biomaterials has been used to be introduced permanently, dissolved over time, or removed at a later stage of the process. These are designed to be biocompatible either in interacting positively or not reacting with cells [72-74]. The biomaterials can be solvents such as nutrient-rich or saline solutions, hydrogels, which are viscous liquids derived from structural proteins, polymers, ceramics, aerogels, or foam scaffolds. Biopolymers, isolated from natural sources, are typically structural proteins such as gelatin or polysaccharides such as alginates that are used as permanent extracellular matrix components. Biodegradable synthetic polymers are typically degradable by hydrolysis and used for temporary structural purposes in the tissue maturation as a sacrificial material. Bioceramics, produced by sintering or melting inorganic raw materials, are designed to produce rigid bodies that have inert, such as calcium phosphates or hydroxyapatites, are often used as implants in medical and dental work designed to replace hard tissue like teeth or to break down and be assimilated over time alike bone structures [75-78]. Scaffold fabrication has been designed using a variety of methods—-such as partial sintering, electrospinning, transient porogen-burning dissolution, gel casting, melt molding and blending, solvent casting and particulate leaching, chemical vapor infiltration, plasma spraying, and many more-before AM technologies became a standard approach — such as inkjet printing, spheroid plotting, stereolithography, micro-extrusion, acoustic ejection, laser-assisted, or multiphoton excitation bioprinting-[79-81]. The choice of printing technology relies on the constraints of the tissue in terms of cell diversity and density, the tissue's volume and morphology, the tissue maturing process, and target application [82-84]. Examples of tissue bioprinting and their biomaterial composition are provided in Table 1.

\section{Integration of Smart Fibers in Bioprinting}

The concept of combining fiber and bioprinting has been introduced before and will be explored further in detail here [5]. A new category of smart fibers emerges in biology interfacing, implanted in three-dimensional tissue constructs to monitor and facilitate the maturing of cells and their interactions at the microscale. Previous work already exists, proving a variety of methods to interact with biological systems, through their mechanical, electrical or chemical properties, their ability transport liquids or gas through the hollow or porous internal structures to deliver or retrieve various agents such as nutrients, oxygen, dopamine, blood and much more. Chemical detection has been shown for specific ambient gases exploiting luminescence-invoked photoconduction, translatable to biological environments [62, 62]. Classical microfluidic cell sorting and population purification have been demonstrated in a fiber where cells in motion are subjected to inertial and dielectrophoretic forces inducing them to migrate to specific locations of the core channel of the fiber if they are dead or alive [93, 94]. The micro-flow behavior is also observable via an in-fiber microfluidic channel lined with a capacitor core [95]. A variety of intracortical probes have been developed using fiber drawing technology, including electrodes, fluid injection channels, and optical waveguides, for electrophysiology and optogenetics applications which were tested in wild-type mice [96]. Pressure and temperature distributed measurements are possible along a fiber using copper electrodes on either side of a core material that responses to pressure or temperature changes [97]. Ultrasound sensing was enabled in fibers using piezoelectric materials to be weaved into fabrics [60]. Long-term microscale implantable devices with nanoscale metallic glass probes and microfluidic features allow localized pharmacological neural stimulation and monitoring [98]. Triboelectric 
Table 1 Examples of structural and functional components for various bioprinted tissues

\begin{tabular}{|c|c|c|c|c|}
\hline Tissue application & Structural (top-down) & Functional (bottom-up) & Printing method & Refs. \\
\hline Vessel & $\begin{array}{l}\text { Silicone } \\
\text { Gelatin-fibrinogen hydrogel } \\
\text { Polyethylene oxide-polypropylene oxide- } \\
\text { polyethylene oxide copolymer }\end{array}$ & $\begin{array}{l}\text { Human umbilical vein endothelial cells } \\
\text { Human neonatal dermal fibroblasts } \\
\text { Human bone marrow-derived mesenchymal } \\
\text { stem cells }\end{array}$ & Microextrusion & {$[85]$} \\
\hline Muscle & $\begin{array}{l}\text { Polycaprolactone } \\
\text { Ethylene oxide and polypropylene oxide } \\
\text { hydrogel (Pluronic F-127) } \\
\text { Gelatin-fibrinogen-hyaluronic acid-glyc- } \\
\text { erol hydrogel }\end{array}$ & Mouse myoblasts & Microextrusion & {$[86]$} \\
\hline Bone & Human osteoprogenitor cells & Nano hydroxyapapatite & Laser-Assisted Deposition & [87] \\
\hline Cartilage & $\begin{array}{l}\text { Gelatin methacrylate } \\
\text { Polyethylene glycol dimethacrylate }\end{array}$ & $\begin{array}{l}\text { Human avascular zone meniscus cells } \\
\text { Human chondrocytes }\end{array}$ & $\begin{array}{l}\text { Stereolithography } \\
\text { Inkjet }\end{array}$ & $\begin{array}{l}{[88]} \\
{[89]}\end{array}$ \\
\hline \multirow[t]{2}{*}{ Cardiac } & Alginate & $\begin{array}{l}\text { Human cardiac-derived cardiomyocyte } \\
\text { progenitor cells }\end{array}$ & Microextrusion & [90] \\
\hline & Biomaterial-free & $\begin{array}{l}\text { Human induced pluripotent stem cell- } \\
\text { derived cardiomyocyte } \\
\text { Fibroblasts } \\
\text { Endothelial cells }\end{array}$ & Bioplotting & [91] \\
\hline Liver & Sodium alginate-calcium chloride solution & $\begin{array}{l}\text { Human induced pluripotent stem cells } \\
\text { Human embryonic stem cells }\end{array}$ & Inkjet & [92] \\
\hline
\end{tabular}

nanogenerators fiber devices for mechanical force detection with surface patterns were designed as a wearable multipoint touch sensor [99]. The triboelectric effect was also used in fiber technology to sense finger bending conditions and breathing monitoring [6]. Another fiber was designed with a porous scaffold as a nerve guidance platform for applications in neurosurgery [100]. A summary of the material composition of the fiber examples discussed and more are shown in Table 2 underlining the variety of composition possible in the fiber fabrication process. Although these fibers were produced with conventional methods such as rolling sheets of materials or hot-pressing milled components, many of the polymers and core materials used in their composition can be 3D printed. These fibers all have a possible application in tissue engineering, in monitoring cell nutrients and growth factors, carbon dioxide concentration, proliferation and density, cell life expectancy, and more.

Fibers can be embedded in a three-dimensional construct with limited interference in the natural state of the biological matter [5], like the array of needles in the Kenzan Method used in bioplotting, which are minimally intrusive [104, 105]. Progress has been made in fiber-tissue interaction including 3D printed, coextruded copper and silicone structures of arbitrary shapes used as a mesh monitoring of a porcine liver model to observe real-time organ displacement of a perfusion-induced edema or for the mechanical sensing of a person's skin facial movement during sound-free verbal communication [26]. This latter metal-core polymer filament was produced by conventional microextrusion under pressure alike typical top-down bioprinting meaning that it is limited to room temperature materials and performances unlike the thermally-drawn fibers reviewed in this publication. Thermally drawn fibers used specifically in bioprinting include impedimetric fiber electrodes to monitor the bioprinted material in terms of cell type, differentiation stage, and survival at the nozzle during the micorextrusion process only [103]. This works shows the multi-faceted uses of fibers as they can be useful at different stages of the bioprinting process. Figure 5 shows how the integration of fibers in tissue is applicable in extrusion-based bioprinting, a method that is also applicable to other bioprinting techniques such as plotting spheroid assemblies, inkjet, piezoelectric, acoustic, and more. In Fig. 5I is illustrated the progression of bioprinting methodology through increasing complexity of architectural and functional control: structure and morphology, cell type development and environment, and the combination of both through the use of emerging technologies such as smart fiber. Alike the Kenzan Method, the fibers are minimally intrusive, with the added value of holding various capabilities such as sensing, microfluidic delivery, electrical conduction, and more, depending on the design 
Table 2 Various compositions of materials used in thermally drawn polymer fibers for biomedical applications

\begin{tabular}{|c|c|c|c|}
\hline Application & Structural cladding materials & Functional core materials & Refs. \\
\hline Motion sensing & Polydimethylsiloxane-urea copolymer & Gallium-indium-tin alloy & {$[6]$} \\
\hline \multirow[t]{2}{*}{ Pressure sensing } & Styrene-ethylene-butylene-styrene & $\begin{array}{l}\text { Conductive polyethylene } \\
\text { Gallium-indium-tin alloy }\end{array}$ & [101] \\
\hline & $\begin{array}{l}\text { Polycarbonate } \\
\text { Polyvinylidene fluoride }\end{array}$ & $\begin{array}{l}\text { Styrene-ethylene-butylene-styrene } \\
\text { Copper }\end{array}$ & [97] \\
\hline \multirow[t]{2}{*}{ Temperature sensing } & Polysulfone & $\begin{array}{l}\text { Germanium-arsenic-selenium-tellerium alloy } \\
\text { Tin-silver alloy }\end{array}$ & [102] \\
\hline & Low-density polyethylene & Copper & [97] \\
\hline Ultrasound communication & Polycarbonate & $\begin{array}{l}\text { Conductive polyethylene } \\
\text { Polyinylidene fluoride trifluoroethylene } \\
\text { Bismuth-tin alloy }\end{array}$ & {$[60]$} \\
\hline \multirow[t]{3}{*}{ Microfluidic device } & Cyclo-olefin copolymer & $\begin{array}{l}\text { Hollow core } \\
\text { Copper } \\
\text { Conductive polyethylene }\end{array}$ & [94] \\
\hline & Polycarbonate & $\begin{array}{l}\text { Hollow core } \\
\text { Conductive polyethylene } \\
\text { Bismuth-tin alloy }\end{array}$ & {$[95]$} \\
\hline & $\begin{array}{l}\text { Polycarbonate } \\
\text { Polyvinylidene fluoride }\end{array}$ & $\begin{array}{l}\text { Hollow core } \\
\text { Copper }\end{array}$ & {$[103]$} \\
\hline Optogenetic device & $\begin{array}{l}\text { Polycarbonate } \\
\text { Cyclo-olefin copolymer }\end{array}$ & $\begin{array}{l}\text { Hollow core } \\
\text { Conductive polyethylene }\end{array}$ & [96] \\
\hline Chemical sensing & Polysulfone & $\begin{array}{l}\text { Selenium-sulfur alloy } \\
\text { Tin-lead alloy } \\
\text { Conductive polycarbonate }\end{array}$ & {$[62,62]$} \\
\hline
\end{tabular}

of the fiber. Figure 5II shows how impressive results have already been made in bioprinting realistic structures of similar mechanical properties to human body elements, such as an aortic valve or an ear. Figure 5III shows the challenging controlled growth of vasculature and neural circuits, using growth factors to stimulate cells to proliferate, differentiate, and secrete desired biological systems in three-dimensional structures and thus create very small segments of real tissue functions. Figure 5IV shows the incorporation of fiber-sensor segments into the bioprinting process of the Bio $\mathrm{X}$ printer by Cellink Inc. to monitor the tissue construct. These fibers, incorporating sensors, transducers, and microfluidic channels, can be externally hooked to a voltmeter, pulse generator, syringe pump, and other control subsystems to monitor and stimulate the growth of the tissue on a large scale, thus integrating into a single methodology the individual state-of-the-art advances in the tissue engineering that exists today. Once the tissue is deemed mature enough, the fibers can be removed with negligible left-over voids that quickly get filled by the interfacing tissue. Fibers can even be composed of biodegradable materials, dissolving as the tissue matures. With dissolving materials, the decay rates of various materials arranged selectively can be timed such that it supports the cells to grow desired tissue features such as epithelial membranes or vascular channels. As demonstrated through a variety of examples, fiber technology has the potential to directly address challenges of bioprinting such as the tradeoff between resolution and volume, monitoring cell type, density, and population ratios, control of cells' proliferation, interactions, differentiation, motion, precise delivery of cell-signaling biomolecules and nutrients, and the management of hazardous and infectious byproducts. The resolution of these elements which are difficult to control during the bioprinting process could yield to a sustainable tissue self-assembly and its homeostasis, and thus emerging technologies such as fiber devices can resolve current important setbacks of tissue engineering and regenerative medicine.

\section{Conclusions}

Recent advances in additive manufacturing setups and materials allow for the gradual replacement of expensive, labor-intensive, and complexity-limited conventional fiber preform fabrication approaches, such as stack-and-draw and variations of CVD with a digitized Computer-Aided Design-Computer-Aided Manufacturing (CAD-CAM) approach based in 3D printing. This shift enables materializing monolithic, mutimaterial preforms with high repeatability, accuracy, and architectural freedom, opening a new frontier in the functional flexibility of the fiber devices. By 

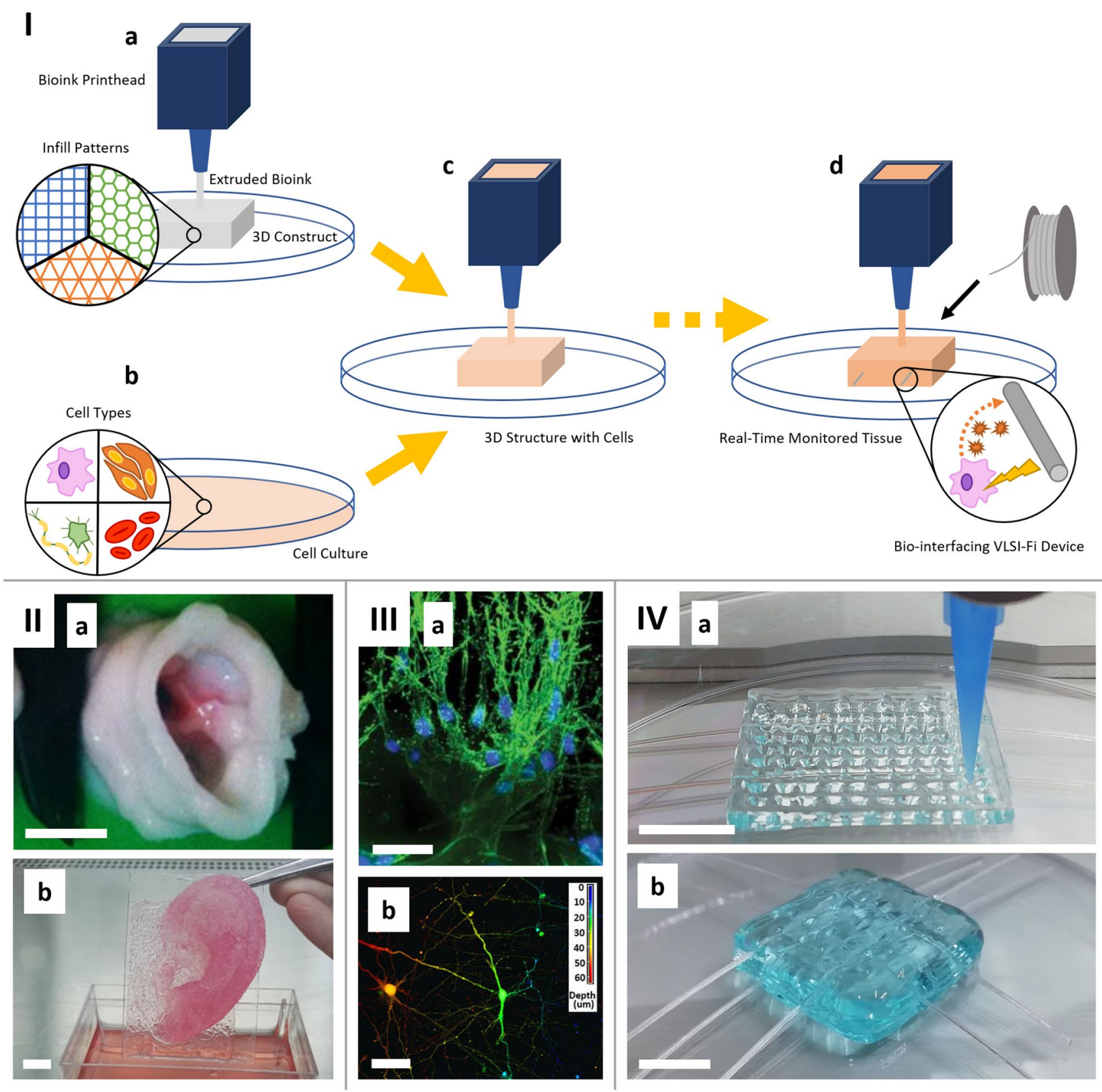

Fig. 5 Bioprinting complexity and optimization. I Evolution of complexity in bioprinted constructs with emerging technologies. Ia Design of the printed extracellular matrix with various scaffold strategies. Ib Culture of cell type populations based on the desired tissue. II Bioprinted structurally heterogenous biological constructs with accurate anatomical morphology as designed in Ia. IIa A poly-ethylene glycol-diacrylate tricuspid aortic valve with an inner diameter of $12 \mathrm{~mm}$ (scale bar=1 cm), adapted from [27]. IIb $8 \mathrm{~cm}$ adult ear structure with accurate morphology composed of a gelatin-alginatefibrinogen bioink and fibroblasts (scale bar $=2 \mathrm{~cm}$ ), adapted from [106]. III Cell type accuracy as defined in Ib. IIIa Multicellular angiogenic sprouting from endothelial cells forming new vessels, where visible fluorescent stains are filamentous actin in green and the nuclei in blue (scale bar $=50 \mu \mathrm{m}$ ), adapted from [107]. IIIb Growth of nucleus gigantocellularis neurons, embryonic mouse hindbrain cells at embryonic day 12.5 , in a gelatin methacrylamide and hyaluronic acid methacrylate hydrogel scaffold (scale bar $=50 \mu \mathrm{m}$ ), image adapted from [108]. IV Conceptual figure of monitored functional accuracy by embedding VSLI-Fi technology in bioprinted constructs. IVa $30 \mathrm{~mm} \times 30 \mathrm{~mm} \times 1 \mathrm{~mm} 2$ D layer printed in commercial polypropylene oxide water soluble gel with a Bio X bioprinter (Cellink, Inc.) with fibers embedded within a construct of low infill providing an array of hollow wells (scale bar $=1 \mathrm{~cm}$ ). IVb $20 \mathrm{~mm} \times 20 \mathrm{~mm} \times 5 \mathrm{~mm}$ $3 \mathrm{D}$ construct printed in commercial polypropylene oxide water soluble gel with a Bio $\mathrm{X}$ bioprinter (Cellink, Inc.) with fibers embedded in a full infill scaffold (scale bar $=1 \mathrm{~cm}$ ) 
taking a recursive manufacturing approach, fibers drawn from 3D printed preforms can be incorporated back into the 3D printing feedstock, imparting the resulting macroscopic objects the functionality of the nano-, micro-, or meso-scale fiber device. In additive manufacturing approaches, where the microstructure control is a challenging, such as bioprinting, incorporation of structured fibers into the print process is one of the viable ways to create anatomical models of tissues and organs with a microstructure typical of realistic tissue, such as microvasculature.

Funding This research is partially supported by IU Collaborative Research Grants (IUCRG) Program, IU Faculty Research Support Program-External Resubmission (FRSP-ER), and IU Emerging Areas of Research (EAR) Program.

\section{Compliance with Ethical Standards}

Conflict of Interest The authors declare no conflict of interests.

Open Access This article is licensed under a Creative Commons Attribution 4.0 International License, which permits use, sharing, adaptation, distribution and reproduction in any medium or format, as long as you give appropriate credit to the original author(s) and the source, provide a link to the Creative Commons licence, and indicate if changes were made. The images or other third party material in this article are included in the article's Creative Commons licence, unless indicated otherwise in a credit line to the material. If material is not included in the article's Creative Commons licence and your intended use is not permitted by statutory regulation or exceeds the permitted use, you will need to obtain permission directly from the copyright holder. To view a copy of this licence, visit http://creativecommons.org/licenses/by/4.0/.

\section{References}

1. Tao G, Shabahang S, Banaei E-H, Kaufman JJ, Abouraddy AF. Multimaterial preform coextrusion for robust chalcogenide optical fibers and tapers. Opt Lett. 2012;37:2751.

2. Jakubowski K, Huang CS, Gooneie A, Boesel LF, Heuberger M, Hufenus R. Luminescent solar concentrators based on melt-spun polymer optical fibers. Mater Des. 2020;189:108518.

3. McCann JT, Marquez M, Xia Y. Highly porous fibers by electrospinning into a cryogenic liquid. J Am Chem Soc. 2006; $128(5): 1436-7$

4. Yan W, Dong C, Xiang Y, Jiang S, Leber A, Loke G, Xu W, Hou C, Zhou S, Chen M, Hu R, Shum PP, Wei L, Jia X, Sorin F, Tao X, Tao G. Thermally drawn advanced functional fibers: new frontier of flexible electronics. Mater Today. 2020;35:168-94.

5. Faccini de Lima C, van der Elst LA, Koraganji VN, Zheng M, Kurtoglu MG, Gumennik A. Towards digital manufacturing of smart multimaterial fibers. Nanoscale Res Lett. 2019;14:209.

6. Dong C, Leber A, Das Gupta T, Chandran R, Volpi M, Qu Y, Nguyen-Dang T, Bartolomei N, Yan W, Sorin F. High-efficiency super-elastic liquid metal based triboelectric fibers and textiles. Nat Commun. 2020;11:3537.

7. Zhang J, Zhang T, Zhang H, Wang Z, Li C, Wang Z, Li K, Huang X, Chen M, Chen Z, Tian Z, Chen H, Zhao L-D, Wei L. Singlecrystal $\mathrm{SnSe}$ thermoelectric fibers via laser-induced directional crystallization: from 1D fibers to multidimensional fabrics. $A d v$ Mater. 2020;32:2002702.

8. Xu B, Ma S, Xiang Y, Zhang J, Zhu M, Wei L. In-fiber structured particles and filament arrays from the perspective of fluid instabilities. Adv Fiber Mater. 2020;2:1-12.

9. Yan W, Nguyen-Dang T, Cayron C, Das Gupta T, Page AG, Qu $\mathrm{Y}$, Sorin F. Microstructure tailoring of selenium-core multimaterial optoelectronic fibers. Opt Mater Express. 2017;4:1388-97.

10. Lydtin H. PCVD: a technique suitable for large-scale fabrication of optical fibers. J Lightwave Technol. 1986;4:1034-8.

11. Jablonowski D. Fiber manufacture at AT\&T with the MCVD process. J Lightwave Technol. 1986;4:1016-9.

12. Abouraddy AF, Bayindir M, Benoit G, Hart SD, Kuriki K, Orf N, Shapira O, Sorin F, Temelkuran B, Fink Y. Towards multimaterial multifunctional fibres that see, hear, sense and communicate. Nat Mater. 2007;6:336-47.

13. Bikas H, Stavropoulos P, Chryssolouris G. Additive manufacturing methods and modelling approaches: a critical review. Int $J$ Adv Manuf Technol. 2016;83:389-405.

14. Wang X, Nie Q, Xu T, Liu L. A review of the fabrication of optic fiber. In: Proc. SPIE 6034, ICO20: Optical Design and Fabrication. SPIE 2006; paper 60341D.

15. Zaki RM, Strutynski C, Kaser S, Bernard D, Hauss G, Faessel M, Sabatier J, Canioni L, Messaddeq Y, Danto S, Cardinal T. Direct 3D-printing of phosphate glass by fused deposition modeling. Mater Des. 2020;94:108957.

16. Gumennik A, Fink Y, Grena BJB, Joannopoulos JD. Highpressure in-fiber particle production with precise dimensional control. Washington: U.S. Patent and Trademark Office; 2018 ((US Patent 10,112,321)).

17. Fink Y, Abouraddy AF, Grena BJB, Gumennik A, Joannopoulos JD, Lestoquoy GR, Wei L. Dynamic in-fiber particle production with precise dimensional control. Washington: U.S. Patent and Trademark Office; 2019. ((U.S. Patent No. 10,406,723)).

18. Wei L, Hou C, Levy E, Lestoquoy G, Gumennik A, Abouraddy AF, Joannopoulos JD, Fink Y. Optoelectronic fibers via selective amplification of in-fiber capillary instabilities. Adv Mater. 2018;29:1603033.

19. Gumennik A, Wei L, Lestoquoy G, et al. Silicon-in-silica spheres via axial thermal gradient in-fibre capillary instabilities. Nat Commun. 2013;4:2216.

20. Loke G, Yuan R, Rein M, et al. Structured multimaterial filaments for 3D printing of optoelectronics. Nat Commun. 2019; 10 :4010.

21. Hart KR, Dunn RM, Wetzel ED. Tough, additively manufactured structures fabricated with dual-thermoplastic filaments. Adv Eng Mater. 2020;22:1901184.

22. Yaman M, Khudiyev T, Ozgur E, et al. Arrays of indefinitely long uniform nanowires and nanotubes. Nat Mater. 2011; 10:494-501.

23. Koraganji VN, Faccini de Lima C, Zheng M, Gumennik, A. Effects of 3D Printed Preform Annealing on Structural and Optical Properties of Fibers. In: CLEO Pacific Rim Conference 2020, OSA Technical Digest. Opt Soc Am. 2020; paper C6H-6.

24. Zheng M, Faccini de Lima C, Koraganji VN, Gumennik, A. 3D printed glass preforms for optical fibers with nonequilibrium cross-sections. In: Conference on Lasers and Electro-Optics, OSA Technical Digest. Opt Soc Am. 2020; paper JTh2C-9.

25. Cook K, Canning J, Leon-Saval S, Reid Z, Hossain M, Comatti J, Luo Y, Peng G. Air-structured optical fiber drawn from a 3D-printed preform. Opt Lett. 2015;40:3966-9.

26. Tong Y, Feng Z, Kim J, Robertson JL, Jia X, Johnson BN. 3D printed stretchable triboelectric nanogenerator fibers and devices. Nano Energy. 2020;75:104973. 
27. Hockaday LA, Kang KH, Colangelo NW, Cheung PYC, Duan B, Malone E, Wu J, Girardi LN, Bonassar LJ, Lipson H, Chu CC, Butcher JT. Rapid 3D printing of anatomically accurate and mechanically heterogeneous aortic valve hydrogel scaffolds. Biofabrication. 2012;4(3):035005.

28. Peters K. Polymer optical fiber sensors-a review. Smart Mater Struct. 2011;20:013002.

29. Zubia J, Arrue J. Plastic optical fibers: an introduction to their technological processes and applications. Opt Fiber Technol. 2001; 7:101-40.

30. Toal PM, Holmes LJ, Rodriguez R, Wetzel ED. Microstructured monofilament via thermal drawing of additively manufactured preforms. Addit Manuf. 2017;16:12-23.

31. Kaufman JJ, Bow C, Tan FA, Cole AM, Abouraddy AF. 3D printing preforms for fiber drawing and structured functional particle production. In: Photonics and Fiber Technology 2016 (ACOFT, BGPP, NP), OSA Technical Digest (online). Opt Soc Am. 2016; paper AW4C.1.

32. Luo Y, Canning J, Zhang J, Peng GD. Toward optical fibre fabrication using 3D printing technology. Opt Fiber Technol. 2020;58:102299.

33. Xu B, Li M, Wang F, Johnson SG, Fink Y, Deng D. Filament formation via the instability of a stretching viscous sheet: physical mechanism, linear theory, and fiber applications. Phys Rev Fluids. 2019;4(7):073902.

34. Xu B, Deng D. Linear analysis of dewetting instability in multilayer planar sheets for composite nanostructures. Phys Rev Fluids. 2020;5(8):083904.

35. Page AG, Bechert M, Gallaire F, Sorin F. Unraveling radial dependency effects in fiber thermal drawing. Appl Phys Lett. 2019;115(4):044102.

36. Ghebrebrhan M, Loke G, Fink Y. Fabrication and measurement of 3D printed retroreflective fibers. Opt Mater Express. 2019;9:3432-8.

37. Luo J, Gilbert LJ, Bristow DA, Landers RG, Goldstein JT, Urbas AM, Kinzel EC. Additive manufacturing of glass for optical applications. In: Proc. SPIE 9738 Laser 3D Manufacturing III. SPIE. 2016; paper 97380Y.

38. Choi HK, Ahsan MS, Yoo D, Sohn I, Noh YC, Kim JT, Jung D, Kim JH. Formation of cylindrical micro-lens array in fused silica glass using laser irradiations. In: Proc. SPIE 8923, Micro/ Nano Materials, Devices, and Systems. SPIE. 2013; paper 89234T.

39. Lin J, Yu S, Ma Y, Fang W, He F, Qiao L, Tong L, Cheng $\mathrm{Y}, \mathrm{Xu} \mathrm{Z}$. On-chip three-dimensional high-Q microcavities fabricated by femtosecond laser direct writing. Opt Express. 2012;20:10212-7.

40. Gattass R, Mazur E. Femtosecond laser micromachining in transparent materials. Nat Photon. 2018;2:219-25.

41. Kotz F, Arnold K, Bauer W, Schild D, Keller N, Sachsenheimer K, Nargang TM, Richter C, Helmer D, Rapp BE. Threedimensional printing of transparent fused silica glass. Nature. 2017;544(7650):337-9.

42. Hed PP, Edwards DF. Optical glass fabrication technology. 2: Relationship between surface roughness and subsurface damage. Appl Opt. 1987;26:4677-80.

43. Luo J, Pan H, Kinzel EC. Additive manufacturing of glass. ASME J Manuf Sci Eng. 2014;136(6):061024.

44. Klein J, Stern M, Franchin G, Kayser M, Inamura C, Dave S, Weaver C.J, Houk P, Colombo P, Yang M, Oxman N. Additive Manufacturing of Optically Transparent Glass. 3D Printing and Additive Manufacturing. 2015; 92-105.

45. Kotz F, Schneider N, Striegel A, Wolfschläger A, Keller N, Worgull M, Bauer W, Schild D, Milich M, Greiner C, Helmer D, Rapp BE. Glassomer-processing fused silica glass like a polymer. Adv Mater. 2018;30:1707100.
46. Nguyen DT, Meyers C, Yee TD, Dudukovic NA, Destino JF, Zhu C, Duoss EB, Baumann TF, Suratwala T, Smay JE, Dylla-Spears R. 3D-printed transparent glass. Adv Mater. 2017;29:1701181.

47. Moore DG, Barbera L, Masania K, Studart AR. Three-dimensional printing of mul-ticomponent glasses using phase-separating resins. Nat Mater. 2019; 212-217.

48. Canning J, Hossain MA, Han C, Chartier L, Cook K, Athanaze T. Drawing optical fibers from three-dimensional printers. Opt Lett. 2016;41(23):5551-4.

49. Chu Y, Fu X, Luo Y, Canning J, Tian Y, Cook K, Zhang J, Peng G. Silica optical fiber drawn from 3D printed preforms. Opt Lett. 2019;44(21):5358-61.

50. Camacho Rosales AL, Núñez Velázquez MMA, Zhao X, Sahu JK. Optical fibers fabricated from 3D printed silica preforms. In Proc. SPIE 11271, Laser 3D Manufacturing VII, SPIE 2020; paper 112710U.

51. Spearing SM. Materials issues in microelectromechanical systems (MEMS). Acta Mater. 2020;48:179.

52. Daniels-Race T. Nanodevices: fabrication, prospects for low dimensional devices and applications. In: Feldman M (ed) Nanolithography: the art of fabricating nanoelectronic and nanophotonic devices and systems. Woodhead Publishing, 2014; pp 399-423

53. Dahman Y. Nanotechnology and functional materials for engineers. 1st ed. Amsterdam: Elsevier; 2017.

54. Yan W, Page A, Nguyen-Dang T, Qu Y, Sordo F, Wei L, Sorin F. Advanced multimaterial electronic and optoelectronic fibers and textiles. Adv Mater. 2019;31:1802348.

55. Gumennik A, Levy EC, Grena B, Hou C, Rein M, Abouraddy AF, Joannopoulos JD, Fink Y. Confined in-fiber solidification and structural control of silicon and silicon-germanium microparticles. Proc Natl Acad Sci. 2017;114:28.

56. Zhang J, Wang Z, Wang Z, et al. In-fibre particle manipulation and device assembly via laser induced thermocapillary convection. Nat Commun. 2019;10:5206.

57. Yan W, Qu Y, Gupta TD, Darga A, Nguyên DT, Page AG, Rossi $\mathrm{M}$, Ceriotti M, Sorin F. Semiconducting nanowire-based optoelectronic fibers. Adv Mater. 2017;29:1700681.

58. Rein M, Favrod VD, Hou C, et al. Diode fibres for fabric-based optical communications. Nature. 2019;560:214-8.

59. Leber A, Dong C, Chandran R, et al. Soft and stretchable liquid metal transmission lines as distributed probes of multimodal deformations. Nat Electron. 2020;3:316-26.

60. Chocat N, Lestoquoy G, Wang Z, Rodgers DM, Joannopoulos JD, Fink Y. Piezoelectric fibers for conformal acoustics. Adv Mater. 2012;24:5327-32.

61. Gumennik A, Stolyarov AM, Schell BR, Hou C, Lestoquoy G, Sorin F, McDaniel W, Rose A, Joannopoulos JD, Fink Y. All-infiber chemical sensing. Adv Mater. 2012;24:6005-9.

62. Gottwald JF. Liquid metal recorder. Washington: U.S. Patent and Trademark Office; 1971. ((US Patent No. 3596285A)).

63. Klebe RJ. Cytoscribing: a method for micropositioning cells and the construction of two- and three-dimensional synthetic tissues. Exp Cell Res. 1988; 179:362.

64. Ozbolat IT. 3D bioprinting: fundamentals, principles and applications. 1st ed. Amsterdam: Elsevier Inc.; 2016.

65. Guvendiren M. 3D bioprinting in medicine: technologies, bioinks, and applications. 1st ed. Berlin: Springer International Publishing; 2019.

66. Ashammakhi N, Ahadian S, Xu C, Montazerian H, Ko H, Nasiri R, Barros N, Khademhosseini A. Bioinks and bioprinting technologies to make heterogeneous and biomimetic tissue constructs. Mater Today Bio. 2019;1:100008.

67. Vijayavenkataraman S, Yan WC, Lu WF, Wang CH, Fuh JYH. 3D bioprinting of tissues and organs for regenerative medicine. Adv Drug Deliv Rev. 2018;132:296. 
68. Hynes RO, Naba A. Overview of the matrisome-an inventory of extracellular matrix constituents and functions. Cold Spring Harb Perspect Biol. 2012;4:a004903.

69. Bonnans C, Chou J, Werb Z. Remodelling the extracellular matrix in development and disease. Nat Rev Mol Cell Biol. 2014; $15: 786$

70. Rozario T, DeSimone DW. The extracellular matrix in development and morphogenesis: a dynamic view. Dev Biol. 2010;341:126.

71. Frantz C, Stewart KM, Weaver VM. The extracellular matrix at a glance. J Cell Sci. 2010; 123:4195.

72. Williams DF. On the nature of biomaterials. Biomaterials. 2009;30:5897.

73. Anderson JM. Biological responses to materials. Annu Rev Mater Res. 2001;31:81.

74. Franz S, Rammelt S, Scharnweber D, Simon JC. Immune responses to implants-a review of the implications for the design of immunomodulatory biomaterials. Biomaterials. 2011;32:6692.

75. Hospodiuk M, Dey M, Sosnoski D, Ozbola IT. The bioink: a comprehensive review on bioprintable materials. Biotechnol Adv. 2017;35:217.

76. Jungst T, Smolan W, Schacht K, Scheibel T, Groll J. Strategies and molecular design criteria for 3D printable hydrogels. Chem Rev. 2016;116:1496.

77. Donderwinkel I, Van Hest JCM, Cameron NR. Bio-inks for 3D bioprinting: recent advances and future prospects. Polym Chem. 2017; $8: 4451$.

78. Murphy SV, Skardal A, Atala A. Evaluation of hydrogels for bio-printing applications. J Biomed Mater Res Part A. 2013;101(1):272.

79. Babaie E, Bhaduri SB. Antitumor photodynamic therapy based on dipeptide fibrous hydrogels with incorporation of photosensitive drugs. ACS Biomater Sci Eng. 2018;4:1.

80. Borovjagin AV, Ogle BM, Berry JL, Zhang J. From microscale devices to 3D printing: advances in fabrication of 3D cardiovascular tissues. Circ Res. 2017;120:150.

81. Forgacs G, Sun W. Biofabrication: micro- and nano-fabrication, printing. Patterning and assemblies. 1st ed. Amsterdam: Elsevier Inc.; 2013.

82. Do AV, Khorsand B, Geary SM, Salem AK. 3D printing of scaffolds for tissue regeneration applications. Adv Healthc Mater. 2015;4(12):1742-62.

83. Guvendiren M, Molde J, Soares RMD, Kohn J. Designing biomaterials for 3D printing. ACS Biomater Sci Eng. 2016;2:1679.

84. Moroni L, Burdick JA, Highley C, Lee SJ, Morimoto Y, Takeuchi S, Yoo JJ. Biofabrication strategies for 3D in vitro models and regenerative medicine. Nat Rev Mater. 2018;5:21-37.

85. Kolesky DB, Homan KA, Skylar-Scott MA, Lewis JA. Threedimensional bioprinting of thick vascularized tissues. Proc Natl Acad Sci USA. 2016;113(12):3179-84.

86. Kang HW, Lee SJ, Ko IK, Kengla C, Yoo JJ, Atala A. A 3D bioprinting system to produce human-scale tissue constructs with structural integrity. Nat Biotechnol. 2016;34(3):312-9.

87. Keriquel V, Guillermo F, Arnault I, Guillotin B, Miraux S, Amédée J, Fricain JC, Catros S. In vivo bioprinting for computer- and robotic-assisted medical intervention: preliminary study in mice. Biofabrication 2010; 2(1)

88. Grogan SP, Chung PH, Soman P, Chen P, Lotz MK, Chen S, D'Lima DD. Digital micromirror device projection printing system for meniscus tissue engineering. Acta Biomater. 2013;9(7):7218-26.

89. Cui X, Breitenkamp K, Finn MG, Lotz M, D'Lima DD. Direct human cartilage repair using three-dimensional bioprinting technology. Tissue Eng Part A. 2012;18(11-12):1304-12.
90. Gaetani R, Doevandans PA, Metz CHG, Alblas J, Messina E, Giacomello A, Sluijter JPG. Cardiac tissue engineering using tissue printing technology and human cardiac progenitor cells. Biomaterials. 2012;33(6):1782-90.

91. Ong CS, Fukunishi T, Zhang H, Huang CY, Nashed A, Blazeski A, DiSilvestre D, Vricella L, Conte J, Tung L, Tomaselli GF, Hibino N. Biomaterial-free three-dimensional bioprinting of cardiac tissue using human induced pluripotent stem cell derived cardiomyocytes. Sci Rep. 2017;7(4566):1-11.

92. Faulkner-Jones A, Fyfe C, Cornelissen DJ, Gardner J, King J, Courtney A, Shu W. Bioprinting of human pluripotent stem cells and their directed differentiation into hepatocyte-like cells for the generation of mini-livers in 3D. Biofabrication. 2015;7(4):044102.

93. Yao J, Zhu G, Zhao T, Takei M. Microfluidic device embedding electrodes for dielectrophoretic manipulation of cells-a review. Electrophoresis. 2019;40:1166.

94. Yuan R, Lee J, Su HW, Levy E, Khudiyev T, Voldman J, Fink Y. Microfluidics in structured multimaterial fibers. Proc Natl Acad Sci USA. 2018;115(46):E10830-8.

95. Dong C, Page AG, Yan W, Nguyen-Dang T, Sorin F. Microstructured multimaterial fibers. Adv Mat Technol. 2019;4(10):1-6.

96. Park S, Guo Y, Jia X, Choe HK, Grena B, Kang J, Park J, Lu C, Canales A, Chen R, Yim YS, Choi GB, Fink Y, Anikeeva P. Onestep optogenetics with multifunctional flexible polymer fibers. Nat Neurosci. 2017;4:612-9.

97. Yu L, Parker S, Xuan H, Zhang Y, Jiang S, Tousi M, Manteghi M, Wang A, Jia X. Flexible multi-material fibers for distributed pressure and temperature sensing. Adv Funct Mat. 2020;30(1908915): $1-8$.

98. Yan W, Richard I, Kurtuldu G, James ND, Schiavone G, Squair JW, Nguyen-Dang T, Das Gupta T, Qu Y, Cao JD, Ignatans R, Lacour SP, Tileti V, Courtine G, Löffler JF, Sorin F. Structured nanoscale metallic glass fibres with extreme aspect ratios. Nat Nanotechnol. 2020;15:875-82.

99. Wang Z, Wu T, Wang Z, Zhang T, Chen M, Zhang J, Liu L, Qi M, Zhang Q, Yang J, Liu W, Chen H, Luo Y, Wei L. Designer patterned functional fibers via direct imprinting in thermal drawing. Nat Commun. 2020; 11(3842).

100. Shahriari D, Loke G, Tafel I, Park S, Chiang P, Yink Y, Anikeeva P. Scalable fabrication of porous microchannel nerve guidance scaffolds with complex geometries. Adv Mater. 2019;31:1902021.

101. Qu Y, Nguyen-Dang T, Page AG, Yan W, Gupta TD, Rotaru GM Rossi RM, Favrod VD, Bartolomei N, Sorin F. Superelastic multimaterial electronic and photonic fibers and devices via thermal drawing. Adv Mat. 2018;30(27):1-8.

102. Bayindir M, Abouraddy AF, Arnold J, Joannopoulos JD, Fink Y. Thermal-sensing fiber devices by multimaterial codrawing. $A d v$ Mat. 2006; 18(7):845-59.

103. Haring AP, Jiang S, Barron C, Thompson EG, Sontheimer H, He JQ, Jia X, Johnson BN. 3D bioprinting using hollow multifunctional fiber impedimetric sensors. Biofabrication 2020; 12(035026)

104. Itoh I, Nakayama K, Noguchi R, Kamohara K, Furukawa K, Uchihashi K, Toda S, Oyama J, Node K, Morita S. Scaffold-free tubular tissues created by a bio-3D printer undergo remodeling and endothelialization when implanted in rat aortae. PLoS One. 2015; 10(12): e0136681.

105. Moldovan NI, Hibino N, Nakayama K. Principles of the kenzan method for robotic cell spheroid-based three-dimensional bioprinting. Tissue Eng - Part B Rev. 2017;23(3):237-44.

106. Pourchet LJ, Thepot A, Albouy M, Courtial EJ, Boher A, Blum LJ, Marquette CA. Human skin 3D bioprinting using scaffoldfree approach. Adv Healthc Mater. 2017; 6 . 
107. Nguyen DHT, Stapleton SC, Yang MT, Cha SS, Choi CK, Galie PA, Chen CS. Biomimetic model to reconstitute angiogenic sprouting morphogenesis in vitro. Proc Natl Acad Sci USA. 2013;110(17):6712-7.

108. Magariños AM, Pedron S, Ml C, Kilinc M, Tabansky I, Pfaff DW, Harley. BAC the feasibility of encapsulated embryonic medullary reticular cells to grow and differentiate into neurons in functionalized gelatin-based hydrogels. Front Mater. 2018;5:40.

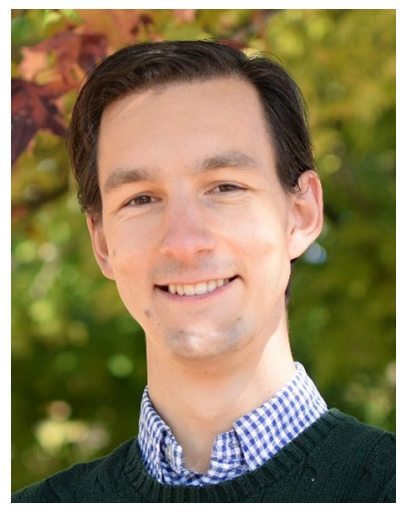

Louis van der Elst is a doctoral Engineering program at Indiana University, majoring in Bioengineering and minoring in Molecular and Nanoscale Engineering, since 2017. He received a Bachelor of Science from the Pennsylvania State University in 2015, majoring in Electrical Engineering and minoring in Engineering Leadership Development. In 2017, he completed a Master of Science in Engineering, in Sustainable Product Creation at the University of Luxembourg. He began his doctoral studies as a member of the Fibers \& Additive Manufacturing Enabled Systems Laboratory (FAMES Lab), specializing in the creation and fabrication of polymeric fibers designed to interface with the cellular environment in biomedical applications for regenerative medicine.

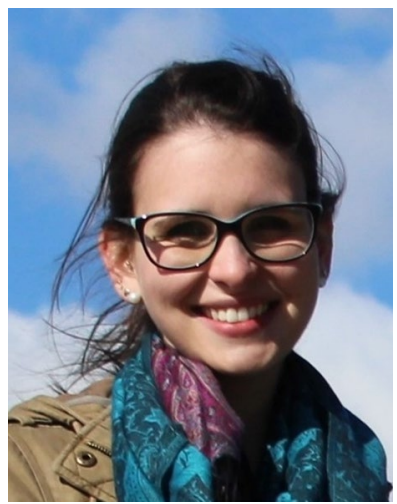

Camila Faccini de Lima is a Ph.D. student in Molecular and Nanoscale Engineering at Indiana University. She received her bachelor's degree in Physics at the Federal University of Rio Grande do Sul, Brazil, and a Master's degree in Experimental Physics by the same university in 2017. She currently conducts research in semiconductor-based fiber-devices for quantum computing and pervasive sensing at the Fibers \& Additive Manufacturing Enabled Systems Laboratory (FAMES Lab) under Dr.

Alexander Gumennik.

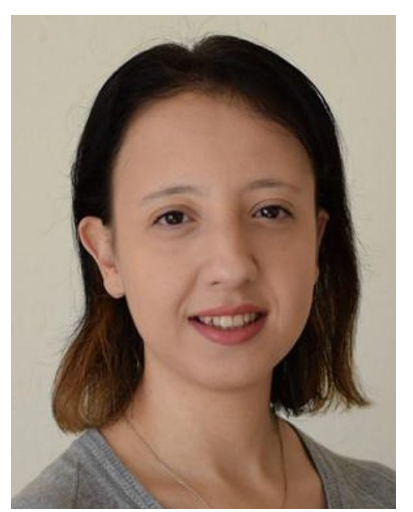
Technical University (ITU) and Montana State University in 2015 with a dual Bachelor of Science degree in Bioengineering. After her graduation, she began to work as a Research Engineer at Optical Microsystems Laboratory (OML) at Koc University for two years. She worked on a portable blood student in the Intelligent Systems

She focuses on embedding polymeric fiber technology into biomedical applications to be used in tissue engineering.

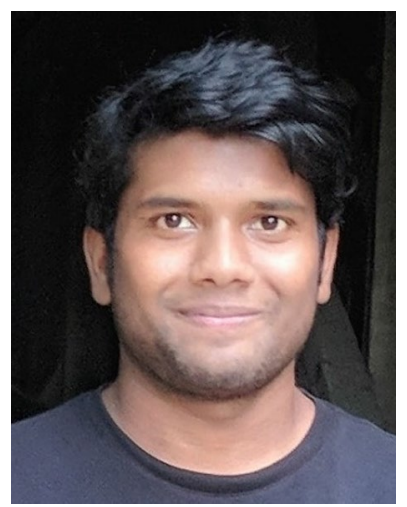

Veda Narayana Koraganji is originally from Andhra Pradesh, India. He received his Bachelor's in Electrical and Electronics Engineering from Lakireddy Bali Reddy College of Engineering (affiliated to JNTUK) in 2015. During his bachelors he specialized in power distribution and industrial automation. $\mathrm{He}$ started his Ph.D. in 2016 in the Intelligent Systems Engineering Department at Indiana University and has been working as an Associate Instructor and conducting research under Prof.

Alexander Gumennik in the FAMES Lab. His research is focused on $3 \mathrm{D}$ printing of electronic circuits, fibers for breathability, passive thermal and humidity management, and structurally colored fibers for consumer usability.

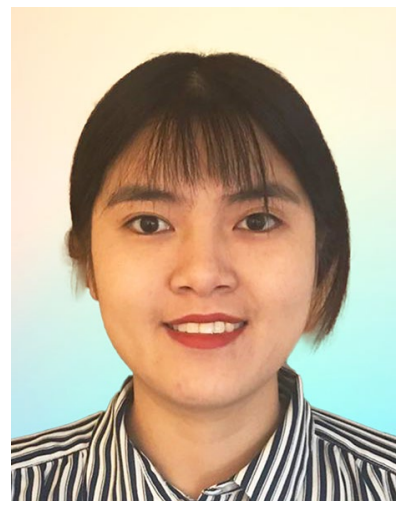

Mengxin Zheng is a Ph.D. student in Intelligent Systems Engineering and a member of the Fibers \& Additive Manufacturing Enabled Systems Laboratory (FAMES Lab). She received her Bachelor's Degree in Materials Science and Engineering at Shan Dong University, in China. Under Prof. Alexander Gumennik's mentorship at the FAMES Lab, her research focuses on pervasive web systems and recursive fiber-device $3 \mathrm{D}$ printing.

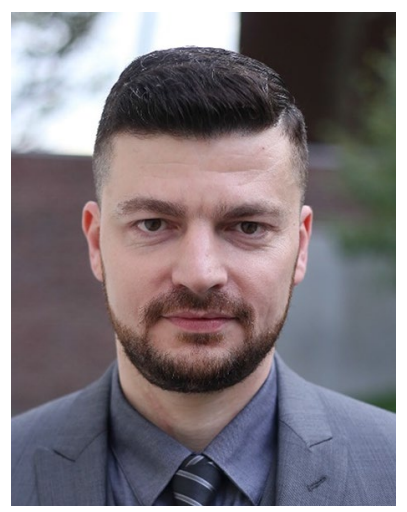

Alexander Gumennik is an Assistant Professor of Intelligent Systems Engineering and the Director of the Fibers \& Additive Manufacturing Enabled Systems Laboratory (FAMES Lab). He received his Ph.D. in Applied Physics (Optoelectronics) from Hebrew University of Jerusalem, Israel, conferred in 2011 under Prof. Aharon J. Agranat's mentorship, following which he has conducted his post-doctoral research in multi-material fiber devices at MIT in Prof. Yoel Fink's group. In 2014 Prof. coagulation measurement system with a single-use optical sensor.
Gumennik joined Formlabs Inc. (Somerville MA, USA)—a "unicorn" startup producing affordable 3D printers - as a Lead Photonics Process Engineer to develop an optical portion of Fuse 1-the first Formlab's Selective Laser Sintering (SLS) printer, commercially launched in June nik's research focuses on functional fiber devices and textiles for sensing, computing, and regenerative medicine, and a range of additive manufacturing approaches in thermoplastics, silica glasses, and biomaterials. 2017. Since joining Indiana University in August 2016, Prof. Gumen- 